Canadian Journal of Plant Science Revue canadienne de phytotechnie

\title{
Characterization of two Winter wheat varieties' responses to freezing in a frigid region of China
}

\begin{tabular}{|r|l|}
\hline Journal: & Canadian Journal of Plant Science \\
\hline Manuscript ID & CJPS-2016-0208.R3 \\
\hline Danuscript Type: & Article \\
\hline Complete List of Authors: & $\begin{array}{l}\text { sun, yinglu } \\
\text { fu, liangshuang } \\
\text { chen, lu } \\
\text { wang, xiaonan } \\
\text { song, yongchao } \\
\text { li, zhuofu; College of Agriculture }\end{array}$ \\
\hline Keywords: & Winter wheat, Cold resistance, BADH, Glycine betaine \\
\hline & \\
\hline
\end{tabular}

\section{SCHOLARONE" \\ Manuscripts}




\title{
Characterization of Two Winter Wheat Varieties' Responses to Freezing in a Frigid Region of China
}

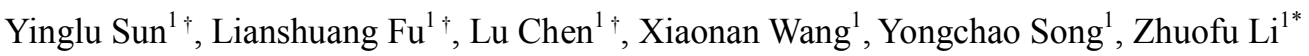 \\ Running title:Glycine Betaine in two cold-resistant winter wheat varieties \\ ${ }^{1}$ Wheat Research Institute, College of Agriculture, Northeast Agricultural University, Harbin, \\ Heilongjiang 150030, China \\ "Corresponding author: Tel: +86-13633612752; lizhuofu1957@,outlook.com(Z.F.Li) \\ †These authors contributed equally to this work
}




\begin{abstract}
Cold stress is one of the main abiotic stresses faced by winter wheat, which results in significant yield loss, especially in the harsh winter of the Heilongjiang province. Glycine betaine (GB), an important osmolyte in higher plants, helps in stabilization of the plasma membrane and its protection from cold stress. In the present study, two winter wheat varieties, Dongnongdongmail (DM1) and Jimai22 (J22), which differ in their cold-resistance were planted under natural conditions and used for analyzing the relative electrical conductivity, malondialdehyde (MDA) content, betaine aldehyde dehydrogenase (BADH) activity, expression of BADH, and the content of GB. The cold-resistant variety, DM1, showed a greater increase in BADH activity and GB content and decreased MDA content than J22 under freezing conditions. GB was observed to have an obvious role in inhibiting the MDA content. This was reflected by the expression of $\mathrm{BADH}$ and enhanced tolerance to cold stress upon GB accumulation, which helped in membrane stabilization. The results of the present study confirmed the role of GB in conferring cold-resistance in the DM1 winter cultivar and could benefit other studies aimed at improving the tolerance of other wheat cultivars as well as other crops.
\end{abstract}

Keywords: Winter wheat, Cold resistance, BADH, Glycine betaine 


\section{INTRODUCTION}

Abiotic stresses cause severe injury and yield loss in crops. Two of the most common abiotic stresses are drought and low temperature, which induce osmotic stress. At temperatures below $0^{\circ} \mathrm{C}$, plants are subjected to freezing injury, caused by the destruction of the protoplasm and could be fatal for the plant (Yan et al. 2011). Many physiological and biochemical mechanisms enable plants to adapt to freezing stress; one of them being the accumulation of compatible solutes, such as polyols, proline, and betaine.

Glycine betaine (GB) is a solute that accumulates in different cellular compartments to maintain the osmotic balance of the cells (Hanson and Scott 1980). It acts as molecular chaperone in the stabilization of the protein tertiary structure (Yancey et al. 1982) under water deficit or salt stress (Hanson and Scott 1980, Weretilnyk and Hanson 1990). In higher plants, glycine betaine is synthesized from choline via a two-step reaction, where betaine aldehyde act as an intermediate compound. The first reaction is catalyzed by choline monooxygenase (CMO; Brouquisse et al. 1989; Yang et al. 2015), whereas the second one is catalyzed by betaine aldehyde dehydrogenase (BADH; Weigel et al. 1986), which convert betaine aldehyde to glycine betaine. To date, $B A D H$ has been cloned from several plants, such as Atriplex hortensis, Spinacia oleracea, Suaeda liaotungensis, Solanum tuberosum and Sesuvium portulacastrum etc. and has been successfully transferred into many plants, including Triticum aestivum, Solanum tuberosum, and Medicago sativa (Ahmad et al., 2014; Di et al. 2015). Transgenic plants carrying the $B A D H$ gene show enhanced tolerance to various abiotic stresses. However, the evaluation for stress tolerance in most of these studies was conducted in glass houses under artificial environment. Furthermore, for simulation of cold stress, the plants were subjected to 
only a few days of cold treatment, with temperatures reaching only a few degrees below zero. In contrast, under field conditions, for example in Heilongjiang Province, winters last for more than 5 months with minimum temperature reaching $-30^{\circ} \mathrm{C}$. In addition, a considerable difference exists between the day- and night-time temperatures of this region. Thus, it is anticipated that the response of plants to stress would differ under laboratory and natural conditions.

Dongnongdongmai 1 (DM1) is a winter wheat cultivar that can survive the harsh winters of Heilongjiang province with an overwintering survival rate exceeding $70 \%$ (Wang et al. 2009, Liu et al. 2013). But the overwintering survival rate of Jimai22 (J22) was no more than $20 \%$. In the present study, we examined the metabolic profiles of GB biosynthesis pathway in order to analyze the cold tolerance of winter wheat. The results of this study not only find one of the reason of cold resistance but also utilization of this cultivar in breeding programme for cold resistance and also help in contribution of osmolyte accumulation to freezing tolerance of this species.

\section{MATERIALS AND METHODS}

\section{Plant Material and Growth Conditions}

Two winter wheat varieties (Triticum aestivum L., $2 \mathrm{n}=6 \mathrm{x}=42$, AABBDD), with significantly different overwintering survival rate, were used in the present study. One variety was Dongnongdongmai 1 (DM1), developed at the Northeast Agricultural University located in Harbin $\left(44^{\circ} 04^{\prime} \mathrm{N}-46^{\circ} 40^{\prime} \mathrm{N}, 125^{\circ} 42^{\prime} \mathrm{E}-130^{\circ} 10^{\prime} \mathrm{E}\right)$, Heilongjiang Province, China and validated by the Heilongjiang Province Crop Variety Certification Committee in 2007. This was the first winter wheat variety that could be grown in the cold areas of China with an overwintering survival rate exceeding $70 \%$, reaching even $90 \%$ in some years (Xie et al. 2015). The other variety used was Jimai 
22 (J22), which was developed by Shandong Province Academy of Agricultural Sciences $\left(34^{\circ} 87^{\prime} \mathrm{N}-37^{\circ} 32^{\prime} \mathrm{N}, 116^{\circ} 45^{\prime} \mathrm{E}-117^{\circ} 57^{\prime} \mathrm{E}\right)$. J22 is the main winter wheat variety cultivated in the Huanghuai wheat growing area and it is a cold-resistance variety in that area. But in Heilongjiang Province, the overwintering survival rates of J22 for six consecutive years (2007-2012) were 0\% (Xie et al. 2015). The field trial was carried out in a completely randomized design. The two winter wheat varieties were planted in the Northeast Agricultural University campus on September 3, 2013 and September 7, 2014, respectively. Each variety was hand-sown in a $30 \mathrm{~m}^{-2}$ plot with 20 rows that were $5 \mathrm{~m}$ long with an inter-row distance of $30 \mathrm{~cm}$. Close spacing of individual plants is $2 \mathrm{~cm}$. Fertilizers were applied at the rate of $17.5 \mathrm{~g}$ $\mathrm{N} \mathrm{m}^{-2}$ as urea and $9.0 \mathrm{~g} \mathrm{P} \mathrm{m}^{-2}$ as single superphosphate to soil before sowing. Field preparations consisted of deep ploughing and harrowing.

\section{Temperature Changes during the Test Period}

As cold acclimation allows hardy plants to develop efficient tolerance mechanisms needed for winter survival (Allard et al. 1998), the wheat varieties used in the present study were acclimated by daytime temperatures below $10^{\circ} \mathrm{C}$, night temperatures above $0^{\circ} \mathrm{C}$, and the average daily temperature below $10^{\circ} \mathrm{C}$ (Wang et al. 2013). In the present study, the acclimation was performed from October 12 to November 14 in 2013 and from October 10 to November 10 in 2014. During the freezing stage, the average temperature was below $0^{\circ} \mathrm{C}$; this stage started from November 15, 2013 and November 11, 2014, in the present study. The temperature (maximum, minimum, and average) details are provided in Fig. 1.

The details of the sampling dates in both the years are shown in Table 1. The sampling days spanned through the initiation of tiller stage to almost the coldest 
period of the winter. The seedlings reached the two or three tiller-stage by November 1 in 2013 and 2014. We investigated the number of seedlings at this stage in order to know the cross-winter survival rate of the winter wheat varieties. The field was covered with snow after November 15 in 2013 and November 21 in 2014. At each sampling date, 30 seedlings were harvested from three accessions of each cultivar. Crowns were cut from each seedling sample. Few crowns from each sample were used to measure the relative electrical conductivity, malondialdehyde (MDA) content, and BADH activity. Other crowns were snap-frozen in liquid nitrogen and stored at $-80^{\circ} \mathrm{C}$ for further estimation of GB content and the expression of $B A D H$ gene. We investigated the number of survival seedlings at April 3 in 2014 and April 6 in 2015 and calculated the cross-winter survival rate.

\section{Detection of Physiological and Biochemical Parameters Related to low}

\section{Temperature Stress}

Plant fresh weight, MDA, relative electrical conductivity (REC), GB content BADH activity, and were done from the crowns $(2-3 \mathrm{~cm}$ shoots part above the roots containing the tillering nodes) of acclimatized DM1 and J22 plants and is repeated using triplicates for both the years.

Plant fresh weight

The seedling fresh weight was scored immediately after removal from the field.

MDA contents

MDA contents were determined according to the published methods of Bates et al. (1973) with minor modifications. Crown tissue $(0.5 \mathrm{~g})$ was homogenized in $3 \mathrm{~mL}$ of $10 \%$ 
trichloroacetic acid (TCA) using a pestle and mortar. The homogenates were then centrifuged at $8000 \mathrm{~g}$ for $10 \mathrm{~min}$. One-mL aliquot of the supernatant was incubated with $1 \mathrm{~mL}$ of $0.5 \%$ thiobarbituric acid (TBA) in $10 \%$ TCA in boiling water for $15 \mathrm{~min}$. After centrifugation at $8000 \mathrm{~g}$ for $10 \mathrm{~min}$, the absorbance of the supernatant was read at 450,532 , and $600 \mathrm{~nm}$.

\section{Relative electrical conductivity}

Relative electrical conductivity was detected using a conductivity meter (DDS-11A, Shanghai, China; Li, 2000). $\quad \mathrm{REC}=\mathrm{R}_{\text {fresh }} / \mathrm{R}_{\text {kill. }}$. Where $\mathrm{R}_{\text {fresh }}=$ electrical conductivity of the water in which the crown was immersed for $1 \mathrm{~h}$, and $\mathrm{R}_{\text {kill }}=$ electrical conductivity of the water after boiling the crown tissue for $15 \mathrm{~min}$ in immersed water.

\section{BADH enzyme activity}

The BADH enzyme activity was measured according to the previously published procedures (Liu et al. 1997). Crown tissue (0.5g) was homogenized in ice-cold 50 $\mathrm{mM}$ potassium phosphate buffer $(2 \mathrm{ml}$; $\mathrm{pH}$ 7.0, 1 mmol L1 EDTA, 1 mmol L1 D-isoascorbic acid, 2\% (w/v) PVP and 0.05\% (w/v) Triton X-100). The homogenates were centrifuged at $12,000 \mathrm{~g}$ for $15 \mathrm{~min}$ at $4{ }^{\circ} \mathrm{C}$, and the supernatants were collected and used in the enzyme assays. BADH activity reaction mixture contained $100 \mathrm{mM}$ K-phosphate buffer (pH8.0), 5mM DTT, $0.5 \mathrm{mM} \mathrm{NAD}^{+}$and $0.5 \mathrm{mM}$ betaine aldehyde. Measurements of fluorescence were carried out with a Hitachi fluorescence spectrometer (U3900, Japan; excitation 340 nm, emission $460 \mathrm{~nm}$ ). Enzyme activity was expressed as initial rates for the reduction of NAD + per mg total protein. 
GB content

GB content was estimated according to methods of Moghaieb et al. (2004). Crown samples used for betaine determination were transferred to vials subjected to methanol extraction, and stored in the dark at $4{ }^{\circ} \mathrm{C}$. The methanol extracts were passed through Dowex-1-H- and Dowex-50-H+ columns. Betaine was eluted with 6M $\mathrm{NH}_{4} \mathrm{OH}$ and then analyzed by HPLC (Agilent 1260 Infinity, Germany) with a SB-C8 Analytical HPLC column. The standard material of betaine (>95\%) was purchased from ChromaDex (CA. USA)

\section{Total RNA Isolation and cDNA Synthesis}

All the samples were ground to a fine powder in liquid nitrogen with a pestle and mortar. Total RNA was extracted using a Plant Total RNA Kit (Tiangen, Beijing, China) according to manufacturer's instructions. The quality and concentration of the total extracted RNA was determined by spectrophotometric analysis. For quantitative real-time polymerase chain reaction (qRT-PCR), $1 \mu \mathrm{g}$ total RNA was used for reverse transcription using Bioneer RocketScript RT PreMix (Seoul, Korea). The resulting cDNA was diluted 5-fold in a final volume of $20 \mu \mathrm{L}$ and used as a template for subsequent PCR analyses.

\section{qRT-PCR Analysis}

$B A D H$ transcript levels were analyzed using qRT-PCR. Reactions were performed in triplicate, in a 96-well plate, with an ABI Prism 7500 Real-Time PCR System (Applied Biosystems, Foster City, CA), using SYBR Green detection chemistry. Reactions were carried out in a total volume of $20 \mu \mathrm{L}$ that contained $10.4 \mu \mathrm{L} 2 \mathrm{X}$ TransStartTop Green qPCR SuperMix with $0.4 \mu \mathrm{L}$ Passive Reference Dye II (50X; Transgene, Beijing, China), $2 \mu \mathrm{L}$ cDNA, and $0.4 \mu \mathrm{L}(300 \mathrm{nM})$ of each gene-specific 
primer. The following standard thermal profile was used for all the PCRs: polymerase activation $\left(94^{\circ} \mathrm{C}\right.$ for $\left.30 \mathrm{~s}\right)$, amplification, and quantification cycles repeated 40 times $\left(94^{\circ} \mathrm{C}\right.$ for $5 \mathrm{~s}, 60^{\circ} \mathrm{C}$ for $34 \mathrm{~s}$, and $72^{\circ} \mathrm{C}$ for $\left.10 \mathrm{~s}\right)$. Finally, a dissociation analysis of the PCR products was performed by running a gradient from 60 to $95^{\circ} \mathrm{C}$ to confirm the presence of a single PCR product and the specificity of qRT-PCR. Glyceraldehyde-3-phosphate dehydrogenase (GAPDH) was used as an internal control. A pair of primers for $B A D H$ was designed using Primer Premier 5.0 software. The relative expression levels were calculated as $2^{-\Delta \Delta \mathrm{CT}}$, where $\Delta \Delta \mathrm{CT}=(\mathrm{CT}$, target CT, actin)time $\mathrm{x}-(\mathrm{CT}$, target $-\mathrm{CT}$, actin)time 0 (Livak and Schmittgen, 2001). The primer sequences used in the reactions are shown in Table 2.

\section{Statistical Analysis}

Statistical analyses of data were performed using SPSS 20.0. Analysis of variance (ANOVA) was used to evaluate the effects on physiological and biochemical parameters in response to low temperature stress.

The relative difference rate (RDR) in various parameters was defined as the ratio of the difference of observed values for DM1 and J22 and the observed value for J22 at each sampling date. The equation used was as follows:

$$
R D R \%=\frac{\text { DataDM1-DataJM22 }}{\text { DataJM22 }} \times 100 \%
$$

\section{RESULTS}

\section{Comparative Analysis of Cross-winter Survival Rate of the Two Wheat Varieties}

From the coldest period to the next April in 2013 and 2014, the average temperature differences were approximately $30^{\circ} \mathrm{C}$ and the lowest temperature was below $-25^{\circ} \mathrm{C}$. Fig. 2 shows that the cross-winter survival rate of DM1 were much higher than in J22, 
which were above $90 \%$ for both the years. The survival rate in J22 was not more than $25 \%$ in two years. It was verified in a previous experiment that DM1 was a more cold-resistant variety than $\mathrm{J} 22$.

\section{Comparative Analysis of Plasma Membrane Stability in Crowns of the Two}

\section{Wheat Varieties At Low Temperature}

There were no obvious differences in the REC between the two wheat varieties at the first sampling date for both the years. However, the REC was significantly lower $(\mathrm{P} \leq 0.05)$ in DM1 than in $\mathrm{J} 22$ in the samples collected on the next seven dates (Fig. 3A). The REC rapidly increased in DM1 in the samples collected on December and November 15. The minimum and the maximum value of REC in the two varieties were obtained in the samples collected on October 1 and January 15. The REC of DM1 ranged from 0.15 to 0.73 and 0.19 to 0.71 in the years 2013 and 2014, respectively, whereas it ranged from 0.19 to 0.84 and 0.21 to 0.82 in $\mathrm{J} 22$ for these years.

With the temperature falling below $0^{\circ} \mathrm{C}$, there was a significant increase in the levels of MDA content in both the varieties. The MDA content in DM1 was lower than that in J22 after November 1. From December 1 to January 15, the MDA content decreased in DM1 (Fig. 3B)

\section{Cold Stress Induces Accumulation of GB and Improves the Activity of BADH}

GB contents did not differ in both cultivars until November (Fig. 3C). However, the contents increased rapidly on November 15 , and were 2 - to 2.25 -fold higher than the content in the October 1 samples. Although the difference in GB content was inconspicuous at basal levels in the two varieties, the total accumulation of GB was $21 \%$ higher in DM1, the more tolerant winter wheat cultivar, than in $\mathrm{J} 22(\mathrm{P} \leq 0.05)$. 
BADH enzyme activity demonstrated a trend similar to that of GB accumulation. The activity in DM1 was 1.3-fold higher than in $\mathrm{J} 22$ on December 1; the highest activity was observed from October 1 to January 15. After December 1, as the temperature continued to fall, the activity of BADH was inhibited in both the varieties (Fig. 3D).

\section{Up-Regulation of BADH Gene Expression in Winter Wheat under Cold Stress}

To determine whether BADH expression was associated with cold stress, RNA extracted from the crown of wheat varieties was used for qRT-PCR analysis. The expression of $\mathrm{BADH}$ in both the varieties showed notable up-regulation with the decrease in temperature from October 1 to December 1 (Fig. 3E). The relative expression reflected the level of the transcript. BADH exhibited similar expression patterns in the two wheat varieties. The maximum transcript level was detected in DM1 on December 1, which was around 6-fold higher than the expression in the October 1 samples. However, in comparison with the BADH expression levels in DM1, the expression level of J22 was lower during the same period. The up-regulated pattern of BADH in the two varieties waned from December 15 to January 15.

\section{GB Protects the Plasma Membrane Stability}

As shown in Fig. 3A-Fig. 3E, for all the sampling dates, the GB content and expression of BADH, as well as its activity, was higher in DM1 than in JM22. In contrast, the REC and MDA content was lower in DM1. These differences increased with the decrease in temperature and revealed the same trend for both the years. To depict the changes in the above-mentioned parameters clearly, relative difference rates were calculated to compare the changing trends of the different parameters during the 
cold treatment period (Fig. 4). The difference rates of BADH expression reached the maximum value on October 1 in both the years, thereafter decreasing in an undulating pattern to $16.12 \%$ and $18.68 \%$ in 2013 and 2014, respectively. Along with the changing $B A D H$ expression, the difference rate of $\mathrm{BADH}$ activity increased from October 1 to January 15 . The difference rates for the GB content in DM1 and J22 were much higher, which changed approximately from $0 \%$ to $40 \%$ in both the years. However, during this period, the difference rates for REC decreased rapidly from $-10 \%$ to $-14 \%$ and MDA content also decreased from $-3 \%$ to $-22 \%$. REC in DM1(samples collected on December 1) was around 30\% lower than in J22 in both the years.. Moreover, damage to the plasma membrane was less severe in DM1 compared toJ22.

\section{DISCUSSION}

Short-term cold stress can hamper spike differentiation in wheat, and result in a great yield reduction. It also affects protein and carbohydrate quality of wheat grain. Therefore, enhancing the tolerance of wheat to low temperatures is very important. In previous research using DM1 and J22, the plant materials were planted in the growth cabinet which cannot reflect the natural environment accurately. But the present study was performed in the field, during winter and, plants response to the stresses was more reliable than in growth cabinet. Cold stress not only affects the lipid composition of plasma membrane but also membrane permeability, which can be assessed by relative electrical conductivity (Zhang et al. 2010). In the present study, the decline in temperature induced an increase in REC by approximately 0.6 in DM1 and 0.7 in J22 (Fig. 3A). The increased REC indicated damage of plasma membrane. However, the extent of injury was lower in DM1 than in J22. Cold stress was also observed to induce an increase in the MDA content (Fig. 3B). The increasing MDA 
content suggested that lipid peroxidation occurred during the stress. The level of lipid peroxidation in cold-resistant variety DM1 was lower than the level in cold-sensitive variety $\mathrm{J} 22$.

GB is an osmoprotectant found in many organisms, including higher plants such as maize (Quan et al. 2004, Chen and Murata 2008), Arabidopsis (Xing and Rajashekar 2001), tomato (Park et al. 2006), and wheat (Ma et al. 2006). It maintains the water balance between plant cells and the environment and stabilizes macromolecules, enzyme activities, and membranes under stress conditions (Joseph et al. 2013). Alteration of the lipid composition of the cell membrane is known to be associated with low temperature tolerance since cell membranes are the first sites of injury (Liu et al. 2008). Chilling stress affects membranes due to the impairment of membrane permeability by the transition of lipids from liquid crystalline phase to gel phase. GB acts a membrane stabilizer contributing to the stabilization and integrity of cellular membranes when plants are subjected to low temperature conditions (Park et al. 2006). As evident from the relative difference rate analysis during the sampling period, the GB content and the activity of BADH in DM1 were much higher than in J22. Concomitantly, the increase in MDA content and REC was lower in DM1 than in J22. All these attributes have been confirmed to be involved in the defense response of plants by protection of the plasma membrane and inhibition of MDA production (Chen and Murata 2008; Zhang et al. 2010). In the present study, GB content increased slowly during the acclimation period. However, there was a significant increase in the GB content in the November 15 samples for both the years when the average temperature was below $0^{\circ} \mathrm{C}$. This finding indicates that $\mathrm{GB}$ accumulation at the end of acclimation period plays an important role in response to the freezing temperatures. In addition, the cold-resistant variety DM1 synthesized and 
accumulated more GB than did the cold-sensitive variety J22 during the cold acclimation and freezing stage, as shown in Fig. 3D. It also had 1.3-fold higher BADH activity than the $\mathrm{J} 22$ variety under cold stress.

In conclusion, our results indicate that the expression of $\mathrm{BADH}$ and the accumulation of GB plays key role in membrane stability which contribute in the cold stress response in the cold-resistant winter wheat variety DM1.

\section{ACKNOWLEDGMENTS}

Financial support for this work was provided by the Natural Science Foundation of Heilongjiang Science and Technology Agency, P. R. China (QC2016026). 


\section{REFERENCES}

Ahmad R, Hussain J, Jamil M, Kim MD, Kwak, SS, Shah MM, Hendawy SE, Suhaibani NA, Rehman SU, 2014. Glycinebetaine synthesizing transgenic potato plants exhibit enhanced tolerance to salt and cold stresses. Pak J Bot 46, 1987-1993.

Allard, F., Houde, M., Ivanov, A., Huner, N.P.A., Sarhan, F. 1998. Betaine improves freezing tolerance in wheat. Plant Cell Physiol. 39, 1194-1202.

Bates, L.S., Waldren, R.P., Teare, I.D. 1973. Rapid determination of free proline for water-stress studies. Plant Soil 39, 205-207.

Brouquisse, R., Weigel, P., Rhodes, D., Yocum, C.F., Hanson, A.D. 1989. Evidence for a ferredoxin-dependent choline monooxygenase from spinach chloroplast stroma. Plant Physiol. 90, 322-329.

Chen, T.H.H., Murata, N. 2008. Glycine betaine: an effective protectant against abiotic stress in plants. Trends Plant Sci. 13, 499-505.

Di, H., Tian, Y., Zu, H., Meng, X., Zeng, X., Wang, Z. 2015. Enhanced salinity tolerance in transgenic maize plants expressing a BADH gene from Atriplex micrantha. Euphytica 206, 775-783.

Hanson, A.D., Scott, N.A. 1980. Betaine synthesis from radioactive precursors in attached, water-stressed barley leaves. Plant Physiol. 66, 342-348.

Joseph, S., Murphy, D., Bhave, M. 2013. Glycine betaine biosynthesis in saltbushes ( Atriplex, spp.) under salinity stress. Biologia, 68(5), 879-895.

Li, H. 2000. Principles and techniques of plant physiological and biochemical experiment (in Chinese), Higher Education Press, Beijing.

Liu, L., Cang, J., Yu, J., Wang, X., Huang, R., Wang, J., Lu, B. 2013. Effects of exogenous abscisic acid on carbohydrate metabolism and the expression levels 
of correlative key enzymes in winter wheat under low temperature. Biosci. Biotechnol. Biochem. 77, 516-525.

Liu X.Y., Li B., Yang J.H., Sui N., Yang X.M., Meng Q.W. 2008. Overexpression of tomato chloroplast omega-3 fatty acid desaturase gene alleviates the photoinhibition of photosystems 2 and 1 under chilling stress. Photosynthesis. 46(2), $185-192$.

Liu, F., Guo, Y., Gu, D., Xiao, G., Chen, Z., Chen, S. 1997. Salt tolerance of transgenic plants with BADH cDNA. Acta Genet. Sin. 24, 54-58.

Livak, K.J., Schmittgen, T.D. 2001. Analysis of relative gene expression data using real-time quantitative PCR and the 2(-Delta DeltaC(T)) method. Methods 25, $402-408$.

Ma, Q.Q., Wang, W., Li, Y.H., Li, D.Q., Zou, Q. 2006. Alleviation of photoinhibition in drought-stressed wheat (Triticum aestivum) by foliar-applied glycine betaine. J. Plant Physiol. 163, 165-175.

Moghaieb, R.E.A., Saneoka, H., Fujita, K. 2004. Effect of salinity on osmotic adjustment, glycine betaine accumulation and the betaine aldehyde dehydrogenase gene expression in two halophytic plants, Salicornia europaea and Suaeda maritime. Plant Sci. 166, 1345-1349.

Park, E.J., Jeknic, Z., Chen, T.H. 2006. Exogenous application of glycine betaine increases chilling tolerance in tomato plants. Plant Cell Physiol. 47, 706-714.

Quan, R., Shang, M., Zhang, H., Zhao, Y., Zhang, J. 2004. Improved chilling tolerance by transformation with betA gene for the enhancement of glycine betaine synthesis in maize. Plant Sci. 166, 141-149.

Wang, X.N., Fu, L.S., Li, Z.F., Sun, Y.L., Wang, Y.B., Liu, C., Wang, J.W. 2009. Morphogenesis and physiological basis in wheat cultivars with different levels 
of cold resistance during cold acclimation and freezing period. Acta Agron. Sin. (in Chinese) 35, 1313-1319.

Wang, X.N., Xie, D.W., Fu, L.S., Sun, Y.L., Li, Z.F., Luan, F.S. 2013. Analysis on membrane stability of crown in winter wheat in frigid region in China. J. Northeast Agric. Univ. 1-11.

Weigel, P., Weretilnyk, E.A., Hanson, A.D. 1986. Betaine aldehyde oxidation by spinach chloroplasts. Plant Physiol. 82, 753-759.

Weretilnyk, E.A., Hanson, A.D. 1990. Molecular cloning of a plant betaine-aldehyde dehydrogenase, an enzyme implicated in adaptation to salinity and drought. Proc. Natl. Acad. Sci. U.S.A. 87, 2745-2749.

Xie, D.W., Wang, X.N., Fu, L.S., Sun, J., Zheng, W., Li, Z.F. 2015. Identification of the trehalose-6-phosphate synthase gene family in winter wheat and expression analysis under conditions of freezing stress. J. Genet. 94, 55-65.

Xing, W., Rajashekar, C.B. 2001. Glycine betaine involvement in freezing tolerance and water stress in Arabidopsis thaliana. Environ. Exp. Bot. 46, 21-28.

Yan, Z., Jing, Y., Jing, C., Lijie, L., Yongchao, M., Junhong, W., Da, Z. 2011. Detection of sugar accumulation and expression levels of correlative key enzymes in winter wheat (Triticum aestivum) at low temperatures. Biosci. Biotechnol. Biochem. 75, 681-687.

Yancey, P.H., Clark, M.E., Hand, S.C., Bowlus, R.D., Somero, G.N. 1982. Living with water stress: evolution of osmolyte systems. Science 217, 1214-1222.

Yang C. L, Zhou Y., Fan J., Fu. Y. H., Shen L.B. 2015 SpBADH of the halophyte Sesuvium portulacastrum strongly confers drought tolerance through ROS scavenging in transgenic Arabidopsis. Plant Physiology and Biochemistry. 96: 377-387. 
Zhang, X.Y., Liang, C., Wang, G.P., Luo, Y., Wang, W. 2010. The protection of wheat plasma membrane under cold stress by glycine betaine overproduction. Biol. Plant. 54, 83-88. 


\section{Figure Captions}

Fig. 1. Details of temperature in the year 2013 and 2014.

Fig. 2. The cross-winter survival rate of two winter wheat varieties in two years. Values shown are mean $\pm \mathrm{SE}$ of three replicates per plant.

Fig. 3. Effect of cold stress on REC, MDA, GB, BADH activity, and BADH expression in the wheat cultivars DM1 and J22 in the year 2013 and 2014. The two winter wheat varieties were planted on the field and sampled 8 times per year. (A) REC, (B) MDA content, (C) GB content, (D) BADH activity, (E) BADH mRNA expression. Signifcance of $\mathrm{di} \square$ erence was tested at $\mathrm{P}=0.05$ using ANOVA post hoc LSD Values shown are mean \pm SE of three replicates per plant.

Fig. 4. Relative difference rate of various parameters between DM1 and J22 cultivars at each sampling date. The RDR was defined as the difference in the observed values in DM1 and J22 divided by the value in J22 at each sampling date. 
Table 1 Sampling Dates

\begin{tabular}{|l|l|l|l|l|l|l|l|l|}
\hline Year & \multicolumn{10}{|c|}{ Dates (month/date) } \\
\hline 2013 & $10 / 1$ & $10 / 15$ & $11 / 1$ & $11 / 15$ & $12 / 1$ & $12 / 15$ & $12 / 30$ & $1 / 15$ \\
\hline 2014 & $10 / 1$ & $10 / 15$ & $11 / 1$ & $11 / 15$ & $12 / 1$ & $12 / 15$ & $12 / 30$ & $1 / 15$ \\
\hline
\end{tabular}


Table 2 Primers used for real-time polymerase chain reaction

\begin{tabular}{cccc}
\hline $\begin{array}{c}\text { Gene } \\
\text { name }\end{array}$ & $\begin{array}{c}\text { Amplicon } \\
\text { size } \\
\text { (base pairs) }\end{array}$ & $\begin{array}{c}\text { GenBank } \\
\text { accession number }\end{array}$ & Forward and reverse primer $5^{\prime} \rightarrow 3^{\prime}$ \\
\hline BADH & 104 & AY050316.1 & $\begin{array}{l}\text { F: GTCTGGCTGGTGCCGTGATTTCTG } \\
\text { R: GAAGCAAGGCTGCGAGCAGTTCAC }\end{array}$ \\
\hline GAPDH & 148 & EF592180.1 & $\begin{array}{l}\text { F: TAAGGGTGGTGCCAAGAAGGT } \\
\text { R: AGCAAGAGGAGCAAGGCAGTT }\end{array}$ \\
\hline
\end{tabular}



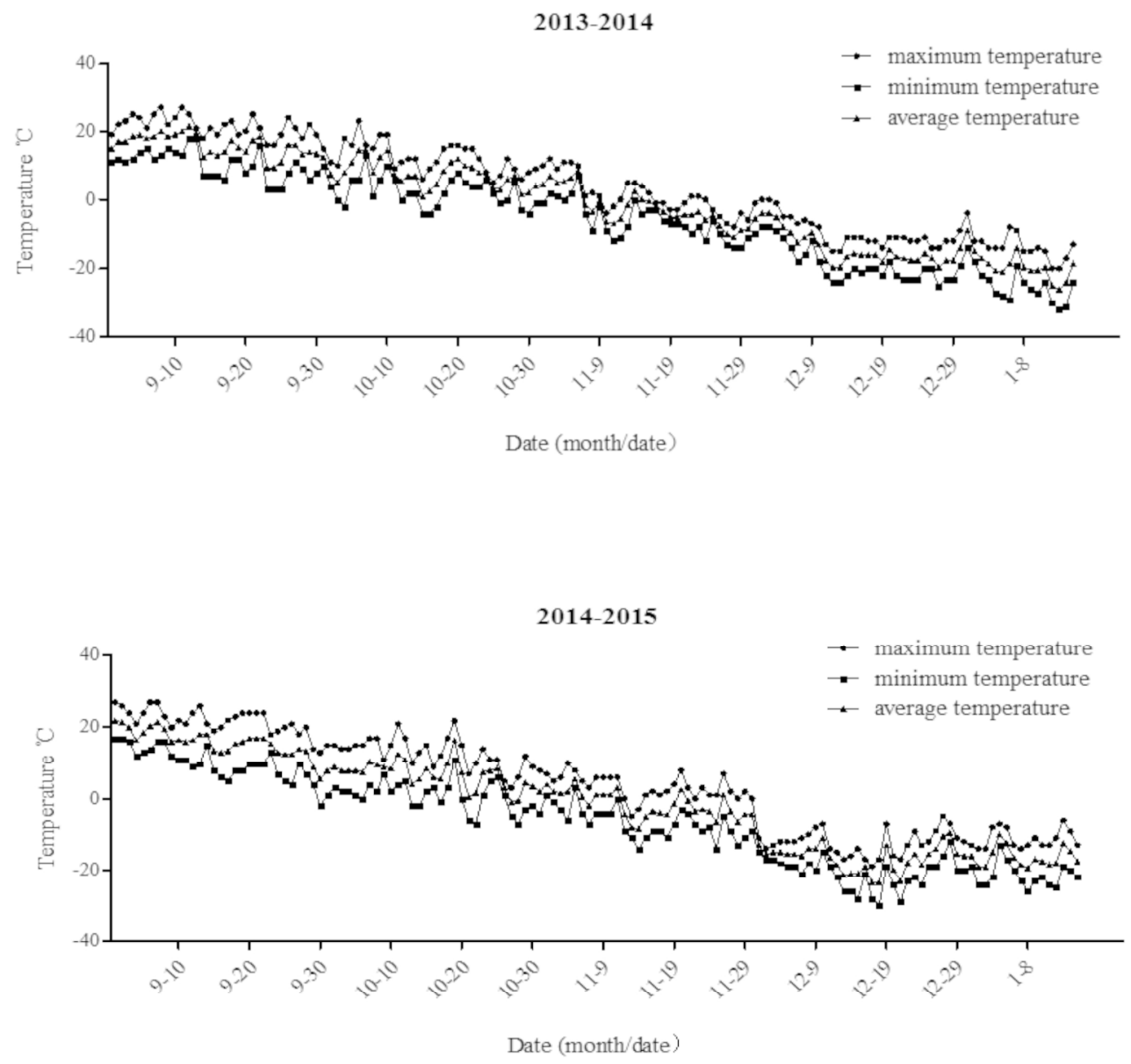

Fig. 1. Details of temperature in the year 2013 and 2014.

$207 \times 229 m m(300 \times 300$ DPI $)$ 


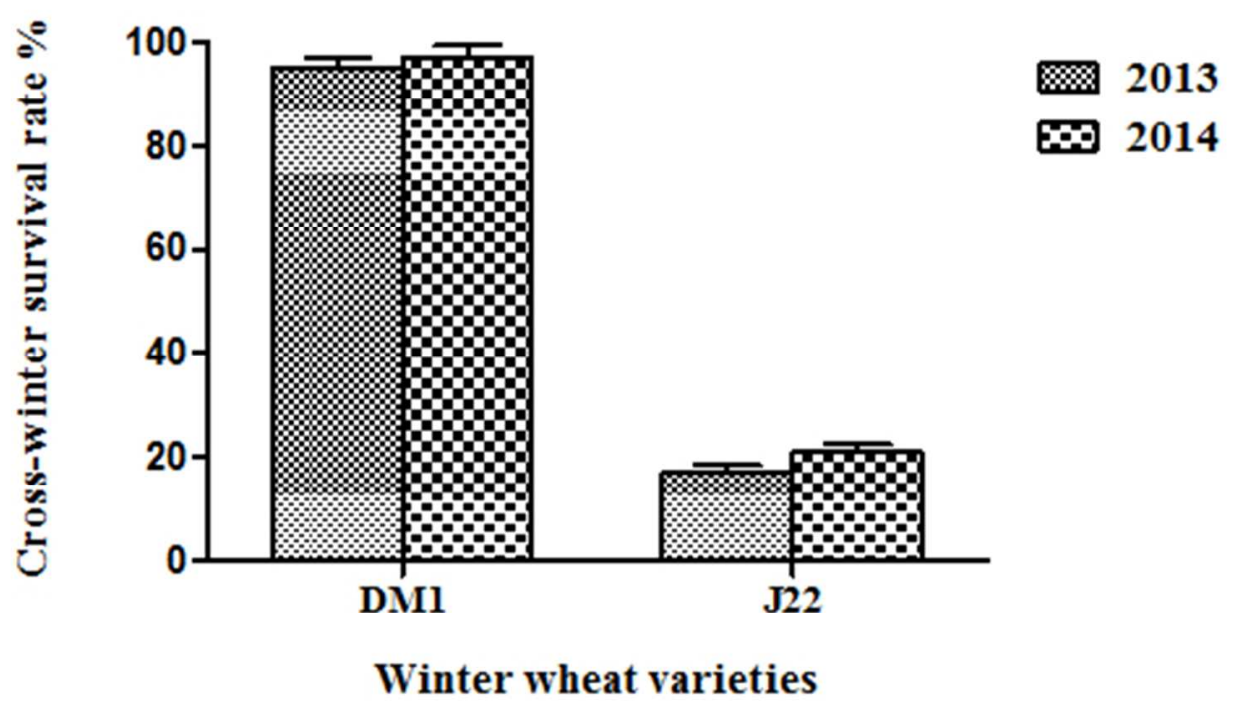

Fig. 2. The cross-winter survival rate of two winter wheat varieties in two years. Values shown are mean \pm SE of three replicates per plant.

$125 \times 75 \mathrm{~mm}(100 \times 100 \mathrm{DPI})$ 
A

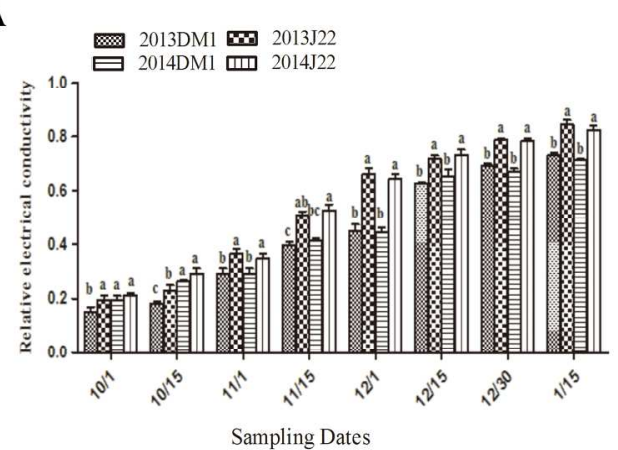

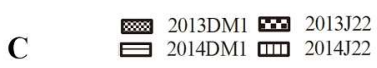

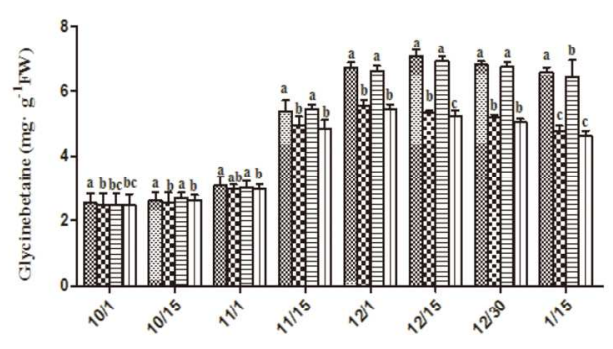

Sampling Dates

E

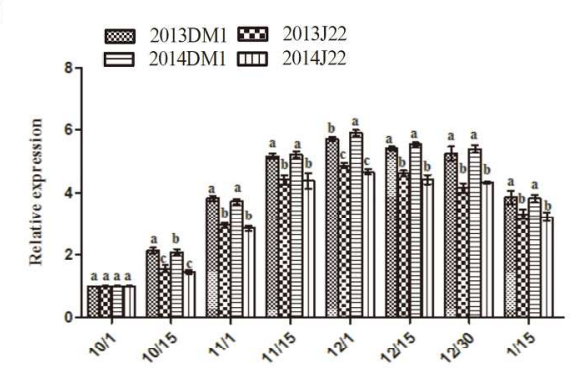

Sampling Dates

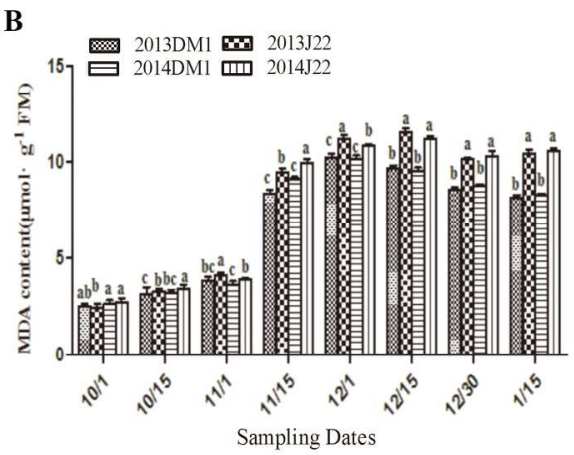

D $\quad$ 2013DM1 $0014 \mathrm{DM} 1001322$

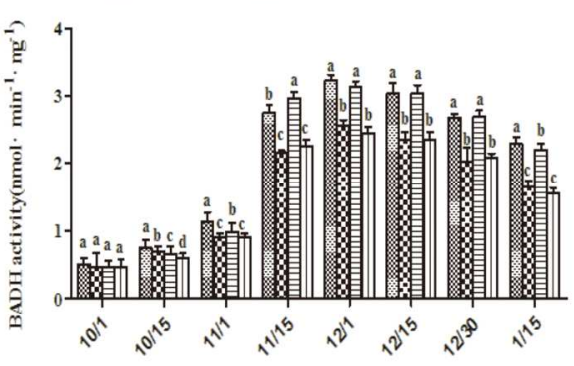

Sampling Dates

Fig. 3. Effect of cold stress on REC, MDA, GB, BADH activity, and BADH expression in the wheat cultivars DM1 and $J 22$ in the year 2013 and 2014. The two winter wheat varieties were planted on the field and sampled 8 times per year. (A) REC, (B) MDA content, (C) GB content, (D) BADH activity, (E) BADH mRNA expression. Signifcance of difference was tested at $P=0.05$ using ANOVA post hoc LSD Values shown are mean \pm SE of three replicates per plant.

$209 \times 253 \mathrm{~mm}(300 \times 300$ DPI $)$ 

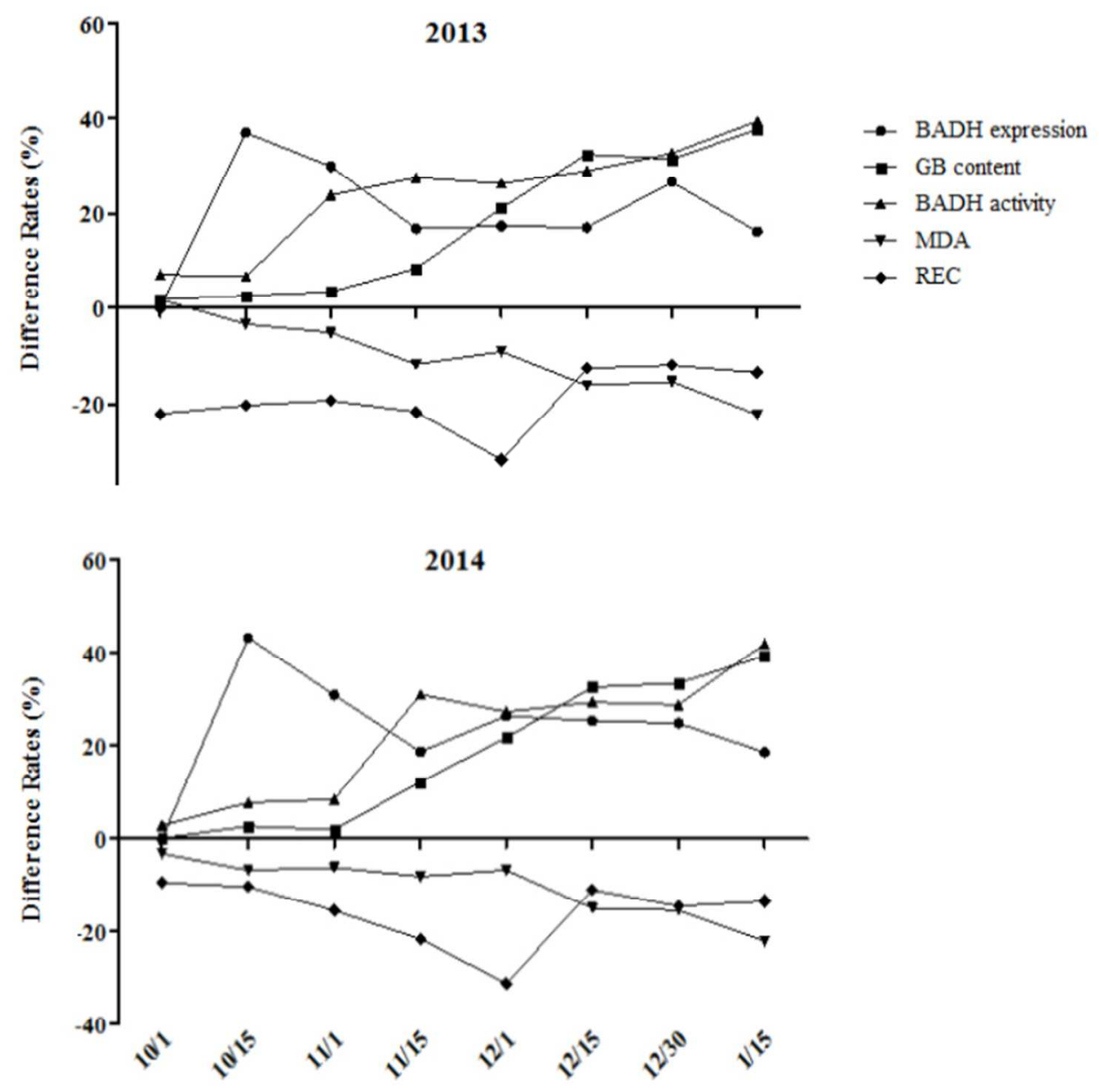

Fig. 4. Relative difference rate of various parameters between DM1 and 322 cultivars at each sampling date. The RDR was defined as the difference in the observed values in DM1 and 322 divided by the value in 322 at each sampling date.

$$
71 \times 74 \mathrm{~mm}(300 \times 300 \mathrm{DPI})
$$

